\title{
Trajetórias Adolescentes e Infração: José, entre a Morte e a Aposta
}

\author{
Jacqueline de Oliveira Moreira ${ }^{1}$ \\ ${ }^{1}$ Pontifícia Universidade Católica de Minas Gerais, \\ MG, Brasil. \\ Andréa Máris Campos Guerra ${ }^{2}$ \\ ${ }^{2}$ Universidade Federal de Minas Gerais, \\ $M G$, Brasil. \\ Frederico Couto Marinho ${ }^{2}$ \\ ${ }^{2}$ Universidade Federal de Minas Gerais, \\ MG, Brasil.
}

\author{
Bráulio Figueiredo Alves da Silva ${ }^{2}$ \\ ${ }^{2}$ Universidade Federal de Minas Gerais, \\ MG, Brasil. \\ Bianca Ferreira Rodrigues ${ }^{1}$ \\ ${ }^{1}$ Pontifícia Universidade Católica de Minas Gerais, \\ MG, Brasil. \\ Ana Carolina Dias Silva ${ }^{1}$ \\ ${ }^{1}$ Pontifícia Universidade Católica de Minas Gerais, \\ MG, Brasil.
}

\author{
Lucas Caetano Pereira de Oliveira ${ }^{2}$ \\ ${ }^{2}$ Universidade Federal de Minas Gerais, MG, Brasil.
}

Resumo: Frente às elevadas taxas de mortalidade e encarceramento de jovens brasileiros negros, pobres e moradores de periferia, apresenta-se pesquisa transdisciplinar que buscou qualificar os eventos, transições e rupturas que marcam suas trajetórias, analisando o ciclo de vida para desvelar seus nexos, movimentos e fatores de risco. Para tanto, partimos do levantamento de Planos Individuais de Atendimento (PIA) de adolescentes em cumprimento de medida socioeducativa para, posteriormente, efetuar uma busca ativa por esses sujeitos, a fim de aplicar um questionário e convidá-los a contarem suashistórias de vida por meio da metodologia de Narrativas Memorialísticas. A partir da análise de um caso que revela o potencial universal de cada vida singular, foram analisados quatro eixos identificados a partir do próprio discurso do jovem, a saber: a violência do Estado, a adolescência, a mortalidade e a aposta. Em contraposição à precariedade e à ausência de amparo a que algumas vidas são lançadas, desvelando a morte, uma aposta decidida, traduzida pela oferta de algum enlaçamento, parece convocar a construção de saídas possíveis.

Palavras-chave: Adolescência, Sistema Socioeducativo, Violência, Transdisciplinaridade.

\section{Adolescent trajectories and infraction: José between death and the wager}

\begin{abstract}
Considering the high rates of mortality and incarceration among young black Brazilians, the poor, and the periphery residents, we present this transdisciplinary research that sought to qualify the events, transitions, and ruptures that mark their trajectories, analysing their life cycle to unveil its links, movements, and risk factors. We started with the survey of Planos Individuais de Atendimento (Individual Care Plans - PIA) of adolescents in compliance with a socio-educational measure, and later with an active search for these subjects, to apply a questionnaire and invite them to tell their life stories by using the methodology of Narrative Memoir. From a case analysis, which reveals the universal potential of each singular life, we analyzed four axes identified from the young man's own discourse, namely: State violence, adolescence, mortality, and wager. In contrast to the precariousness and the lack of support in their lives, risking death, a determined wager, in the form of an unsavory cooperation, may create possible way outs.
\end{abstract}

Keywords: Adolescence, Socio-educational System, Violence, Transdisciplinarity. 


\title{
Trayectorias e Infracciones de Adolescentes: José, entre la Muerte y la Apuesta
}

\begin{abstract}
Resumen: Ante las altas tasas de mortalidad y encarcelamiento de jóvenes negros brasileños, pobres y residentes en la periferia, se presenta una investigación transdisciplinaria que busca calificar los eventos, transiciones y rupturas que marcan sus trayectorias, analizando el ciclo de vida, desvelando sus vínculos, movimientos y factores de riesgo. Para ello, se partió dela encuesta de Planos Individuais de Atendimento ("Planes de Atención Individualizados") de adolescentes en cumplimiento de medida socioeducativa para luego realizar una búsqueda activa de estos temas con el fin de aplicarles un cuestionario e invitarlos a contar sus historias de vida utilizando la metodología de Narrativas Memorialistas. A partir del análisis de caso, que revela el potencial universal de cada vida singular, se analizaron cuatro ejes identificados a partir del propio discurso del joven: la violencia del Estado, la adolescencia, la mortalidad y la apuesta. En contraste con la precariedad y la falta de apoyo a la que se arrojan algunas vidas, desvelando la muerte, una apuesta decidida, traducida en el ofrecimiento de algún vínculo, parece llamar a la construcción de posibles salidas.
\end{abstract}

Palabras clave: Adolescencia, Sistema Socioeducativo, Violencia, Transdisciplinariedad.

\section{Introdução}

Os homicídios são hoje a principal causa de morte entre jovens no Brasil e atingem especialmente jovens pobres e negros, do sexo masculino, moradores das periferias de áreas metropolitanas dos grandes centros urbanos. Nas Notas de Homicídios 4 do autor do Mapa da Violência, publicadas em 2017, foi ressaltado o aumento da mortalidade entre negros na população jovem brasileira, comparada à mortalidade entre jovens brancos, realidade recorrente ao longo dos anos. Interessante notar que o Brasil figura em terceiro lugar no ranking mundial de assassinato de crianças e jovens, precedido somente por México e El Salvador, sendo que "De 1980 a 2014, a taxa de homicídio da população na faixa de 0 a 19 anos de idade passou de 3,1 por 100 mil habitantes para 18,1 um salto de 483,9\%" (Waiselfisz, 2017, pp. 5-6).

Porém, se faz importante pontuar que essa taxa flutua dependendo da idade da vítima: no primeiro ano de vida, há um índice relativamente alto de violência (3,7 por $100 \mathrm{mil}$ ), que novamente torna-se expressivo a partir dos 12 anos, momento em que se observa um crescimento acentuado que chega ao pico nos 16 e 17 anos. Como aponta o autor no relatório específico de homicídios de crianças e adolescentes no Brasil, "com 16 anos de idade, em 2014, foram vitimados 1.686 adolescentes: 4,6 por dia. Já as vítimas adolescentes com 17 anos de idade somaram 2.267: 6,2 por dia" (Waiselfisz, 2017, p. 7).

Segundo o Estatuto da Criança e do Adolescente (ECA), o crime perpetrado por um adolescente é qualificado como infração, dada a inimputabilidade do menor de 18 anos (Lei n. 8.069, 1990). O ato infracional é equivalente ao crime, em correspondência ao Código Penal, e sua pena é remetida e substituída por medida socioeducativa, que pode corresponder a: "I - advertência; II - obrigação de reparar o dano; III - prestação de serviços à comunidade; IV - liberdade assistida; V - inserção em regime de semiliberdade; VI - internação em estabelecimento educacional" (Lei n. 8.069, 1990, p. 58).

A execução das medidas socioeducativas no Brasil é regulamentada pelo Sistema Nacional de Atendimento Socioeducativo (Sinase) e deve buscar a responsabilização e a reparação, sempre que possível, das consequências lesivas do ato infracional praticado pelo adolescente, sem deixar de considerar sua integração social e a garantia de seus direitos. A instituição do Plano Individual de Atendimento (PIA), em regime de prestação de serviços à comunidade, liberdade assistida, semiliberdade ou internação, se constitui enquanto um movimento na direção da garantia desses direitos, uma vez que permite a gestão das atividades desenvolvidas com o adolescente a partir da coparticipação dele mesmo e de sua família (Lei n. 12.594, 2012). Trata-se, portanto, de um avanço das políticas públicas voltadas à infância e à juventude no campo de responsabilização e protagonismo, garantindo direitos fundamentais, bem como atendimento que considera o contexto e singularidades (Moreira, Albuquerque, Rocha, Rocha, \&Vasconcelos, 2015). 
Na cidade de Belo Horizonte, capital do estado de Minas Gerais e lócus de realização desta investigação, os adolescentes apreendidos pela força policial são encaminhados para o Centro Integrado de Atendimento ao Adolescente Autor de Ato Infracional (CIA/BH), um local que visa oferecer atendimento mais rápido e efetivo por congregar, num único espaço físico, uma equipe interinstitucional, que abrange desde juízes, promotores e defensores públicos, até delegados de polícia. Ou seja, trata-se de uma integração de operações, na qual o adolescente é recebido por uma autoridade policial do local e passa por uma audiência preliminar a fim de se apurar os atos infracionais, assim como eventuais execuções de medidas socioeducativas ou protetivas, localizadas na Justiça da Infância e da Juventude. O perfil do adolescente atendido concentra-se na faixa entre 14 e 17 anos $(87,6 \%)$, raças parda e negra $(68,8 \%)$ e escolaridade entre a $5^{\mathrm{a}}$ e a $7^{\mathrm{a}}$ série (50,8\%). Além disso, apenas cinco atos infracionais responderam por $75 \%$ das apreensões de adolescentes no período de 2005 a 2008: tráfico (22,6\%), roubo (19,9\%), furto $(12 \%)$, posse ou porte de arma $(11,7 \%)$ e uso de drogas (9,3\%) (Prefeitura de Belo Horizonte, 2013).

Diante disso, ressalta-se que o perfil da juventude atravessada pelas mais altas taxas de homicídio do país também compõe a maior parcela de jovens às voltas com a justiça juvenil ou criminal, o que suscita um importante questionamento ético a respeito da negligência quanto à responsabilidade social pela juventude. Nesse sentido, fazemos coro à análise que abre a apresentação do primeiro Mapa de Homicídios do Brasil, de 1998:

Não acreditamos que a juventude seja produtora de violência. As novas gerações, mais que fatores determinantes da situação de nossa sociedade, são um resultado da mesma, espelho onde a sociedade pode descobrir suas esperanças de futuro e também seus conflitos, suas contradições e, por que não, seus próprios erros (Waiselfisz, 1998, p. 09).

Essa análise indica a necessária reflexão da conjuntura sócio-subjetiva e político-discursiva que qualifica, como pano de fundo, a questão da criminalidade e da mortalidade juvenis, lembrando-nos de que há processos sociais e simbólicos nela implicados, além dos processos subjetivos, econômicos e políticos que envolvem o próprio jovem.
Face a esse quadro, colocamo-nos a trabalho na pesquisa transdisciplinar "Curso de Vida e Trajetória Delinquencial: Um estudo exploratório dos eventos e narrativas de jovens em situação de vulnerabilidade", aprovada pelo Comitê de Ética em Pesquisa da Universidade Federal de Minas Gerais sob o CAAE: 89451118.3.1001.5149. Nosso objetivo era o de qualificar os eventos, transições e rupturas que marcam as trajetórias de jovens que passaram pelo sistema socioeducativo, analisando o ciclo de vida para desvelar seus nexos, movimentos e fatores de risco (Moreira, Rena, Bolaños, \& Oliveira, 2019; Guerra, Marinho, Silva, \& Lelles, 2019; Lima, Wermelinger, Caetano, \& Silva, 2019). Assim, procederemos no presente trabalho à análise do caso de José (nome fictício), trabalhando sobretudo na articulação entre psicanálise e sociologia, retomando a literatura clássica sobre curso e trajetórias de vida e buscando atualizar com dados empíricos a análise da trajetória infracional de jovens pobres, negros e marginalizados, localizando os pontos de virada que demarcam momentos decisivos para entrada, permanência ou desistência da relação com o crime (Rolim, 2018; Sampson \& Laub, 2005).

A análise do caso revela o potencial universal de cada vida singular, uma vez que partimos da perspectiva freudiana que rejeita a oposição clássica entre psicologia social e individual. Como aponta Fernandes (2008), o conceito de identificação se constitui enquanto peça chave nesse processo, pois demonstra como o eu é formado, desde o princípio, a partir do outro. Assim,

A discussão metapsicológica do sujeito é realizada com referência à cultura e, em correspondência, a discussão sobre cultura, nos termos especificamente psicanalíticos, só pode ser realizada com referência ao pulsional. A aplicação dos conceitos metapsicológicos à problematização da cultura é válida porque o empreendimento de Freud pelo tema cultural não consiste simplesmente na aplicação da teoria à um campo novo. Trata-se de admitir a cultura como campo que influencia e se funde à própria construção metapsicológica (Fernandes, 2008, p. 133).

Trabalharemos este caso, batizado com o nome masculino mais comum do Brasil, guiados pelo operador "Querendo ou não". Do ponto de vista da psicanálise, esse operador indica as modulações dos circuitos pulsionais do sujeito - força constante 
que, do interior do organismo, atua no psiquismo e da qual não se consegue escapar (Freud, 1915/1996) e, do ponto de vista sociológico, leva a refletir sobre como as redes nas quais esse sujeito se insere e como as relações sociais estabelecidas no interior delas modelam as estruturas de oportunidades, as expectativas relacionadas e a própria autoimagem do sujeito (Merton, 1966; Goffman, 2007).

Nos guiaremos por quatro eixos identificados no próprio discurso do jovem, a saber: a violência do Estado, a adolescência, a mortalidade e a aposta. Como destacam Dantas, Dantas e Cabral (2020), a violência policial tem aumentado, com abordagens que geram, muitas vezes, desfechos letais e que são alimentadas pelo racismo, preconceito e impunidade. Tal violência atinge sobremaneira a população adolescente, como apontado anteriormente por meio da interseção entre os que mais morrem e os que estão às voltas com a justiça juvenil, sendo importante destacar os desafios próprios dessa faixa etária que tornam ainda mais complexa a nossa análise.

Como nos lembram Moreira, Rosário e Santos (2011), pensar a adolescência apenas como uma construção cultural desconsidera o trabalho psíquico necessário à criança para sua inserção no mundo adulto, que se inicia com o processo de desligamento da autoridade dos pais. Entretanto, para que esse desligamento ocorra, é preciso que haja uma inconsistência na imagem dos pais, deixando o sujeito desamparado diante da falta de respostas para as principais questões do mundo adulto. É nesse ponto que a aposta pode se constituir enquanto uma saída para o desamparo em uma busca desenfreada por respostas, pois o sujeito se constitui ao mesmo tempo em que constitui subjetivamente o Outro.

\section{Procedimentos metodológicos}

A pesquisa configura-se enquanto um estudo exploratório, de abordagem quantitativa e qualitativa, que buscou qualificar os eventos, transições e rupturas que marcam as trajetórias dos jovens e adolescentes ao longo do seu ciclo de vida, desvelando seus nexos, movimentos e fatores de risco. Em um primeiro momento, a pesquisa buscou informações sobre a trajetória de vida e trajetória infracional dos jovens nos documentos oficiais, especificamente no PIA. Essa etapa consistiu no levantamentodeinformaçõesquantitativasequalitativaspor meio da análise documental de 373 PIA, entre novembro e dezembro de 2016, em parceria com o CIA/BH.
Os 373 jovens que compõem a amostra nasceram entre 1994 e 2003. Os adolescentes do sexo masculino correspondem a 88,5\% e os pretos e pardos representam $80 \%$ do total. Cerca de $52,5 \%$ dos jovens residiam apenas com a mãe, das quais $55,2 \%$ tinham escolaridade inferior a nove anos de estudo. Desse modo, grande parte trabalhava em ocupações de baixo status socioeconômico, como domésticas, faxineiras ou auxiliares de serviços gerais. Não há informações sobre 71,6\% dos pais, mas para esses poucos pais sobre os quais há dados estatísticos, verifica-se a mesma tendência observada entre as mães: baixa escolaridade e ocupações manuais precárias. Assim, vemos que a situação socioeconômica dessas famílias pode ter um impacto sobre a realidade de evasão escolar que caracteriza o público da Justiça Juvenil: $77,1 \%$ dos jovens estavam em situação de defasagem idade-série. De acordo com Salata (2019), que analisou razões para evasão escolar entre jovens no Brasil, "o nível socioeconômico da família de origem tende a se mostrar um dos fatores explicativos mais importantes sobre a evasão" (p. 106).

Além disso, 42,9\% admitiram usar drogas lícitas e $59 \%$ admitiram o uso de drogas ilícitas. Cerca de $38,7 \%$ dos adolescentes estavam cumprindo medida socioeducativa por roubo, $25,1 \%$ por tráfico de drogas e $10,9 \%$ por furto. Assim, somente esses três atos infracionais são responsáveis por $74,7 \%$ das infrações respondidas por esses jovens naquele momento, sendo que $40 \%$ dos adolescentes já haviam passado anteriormente pelo Sistema de Justiça Juvenil.

Assim, chegamos a uma lista de jovens que tiveram uma ou mais passagens registradas em função do cometimento de ato infracional. Essa lista serviu de base para a execução da segunda etapa da pesquisa, a proposta de registro das Narrativas Memorialísticas (Guerra, Moreira, Oliveira, \& Lima, 2017), uma estratégia de pesquisa psicanalítica de fenômenos sociais que comporta as ficções, fixações e fantasias que perpassam os processos inconscientes atravessados por elementos sócio-políticos. Uma vez que a maioria dos PIA analisados continha apenas referências territoriais, sem apresentar outros contatos, decidiu-se pela busca ativa desses jovens, a partir dos endereços dispostos nos PIA, a fim de alcançarmos nossa população de pesquisa.

Uma equipe de pesquisadores(as) do campo da Psicanálise e da Sociologia, composta por professores(as) e alunos(as) de graduação e pós-graduação, organizou um plano de trabalho de campo que envolvia desde o mapeamento oficial das regionais 
em que se distribuíam os endereços, bem como dos equipamentos das políticas públicas de saúde, do serviço social e da segurança pública, até agenda de reuniões com tais instituições para planejamento da aproximação territorial do grupo. A depender da configuração mapeada em termos de levantamento de ocorrência de conflitos no território, uma dupla de pesquisadores - eventualmente acompanhada de um representante de dispositivos da rede de políticas públicas - direcionava-se até o endereço que dispunha a partir da análise documental, em busca do jovem referido por nome próprio e nome da mãe, e não necessariamente pela passagem no sistema infracional.

Tratou-se de estratégia metodológica imprescindível, tendo em vista que a proposta das Narrativas Memorialísticas convida o sujeito a apresentar sua história de vida de forma a construir sua ficção subjetiva do ponto de onde os circuitos pulsionais e suas representações o convocam (Guerra, Moreira, Oliveira, \& Lima, 2017). A história de vida também revela como o sujeito se relaciona com o contexto exterior, as crenças e formas de alteridades, uma vez que a formação da identidade (ou autoimagem) dos sujeitos e o desempenho de papéis sociais é um processo relacional entre os indivíduos, os grupos e as instituições (Goffman, 2007).

Assim, entendemos que referen ciar apenas o nome do jovem abre espaço para a construção de sua apresentação sem necessariamente apreendê-lo em um tecido discursivo pré-conceituado. Essa etapa em território também abarcava a aplicação de um questionário, instrumento que foi desenvolvido no contexto das reuniões do grupo de pesquisa e que foi avaliado em etapa de pré-teste, que consistiu em sua aplicação em adolescentes de escola pública da região metropolitana de Belo Horizonte. Entendemos, no processo de análise da investigação, que esse instrumento permitiu a triangulação das informações - dos PIA e das Narrativas Memorialísticas - e a consideração da pluralidade de processos concretos de socialização e de trajetórias dos sujeitos participantes da pesquisa, indicando-nos pontos de rupturas que tensionavam o relato institucional ou pessoal, o que nos apontou, por vezes, elementos contraditórios imprescindíveis na apreensão da multiplicidade e complexidade das vivências.
Na seleção dos jovens para a construção das narrativas de vida e aplicação do questionário, considerou-se apenas adolescentes residentes no município de Belo Horizonte. Tendo em vista o tempo de execução da pesquisa (2016-2019), bem como as especificidades das incursões territoriais da amostra inicial de 373 jovens, realizamos um mapeamento de 109 nomes espalhados em 6 regionais do município de Belo Horizonte. Conseguimos realizar 200 horas totais de idas a campo, com uma média de cinco endereços visitados por dia de trabalho, efetuado por duplas interdisciplinares um pesquisador pertencente ao campo da psicanálise e outro ao da sociologia -, totalizando 109 endereços visitados. Nas visitas, a partir dos endereços cadastrados quando do atendimento socioeducativo, buscávamos os jovens batendo à porta das casas. Os efeitos e as dificuldades foram vários: o acesso a alguns endereços era difícil, por falta de numeração das casas ou pelos nomes das ruas; alguns jovens haviam migrado, mudando de endereço e, apesar da busca, não conseguimos as informações dos novos endereços residenciais; e, em alguns casos, os familiares ou vizinhos nos informaram que se encontravam ligados ao sistema prisional ou que haviam falecido.

Dentre os endereços em que foi possível localizar os jovens, alguns negaram participar da pesquisa, às vezes assumindo, declaradamente, uma posição de suspeição em relação aos investigadores. Tal posicionamento nos remeteu aos achados de outra pesquisa com a socioeducação, sob a ótica da psicanálise de orientação freudo-lacaniana, na qual se investigou a modalidade da transferência (Guerra, Broide, Moreira, \& Aranha, 2015). Dentre aqueles que aceitaram participar, foi necessário visitar os endereços diversas vezes, em busca por horários e dias em que encontrássemos os jovens em casa e com tempo disponível para participar. Pontuamos ainda que com o auxílio do levantamento de dados da Secretaria de Estado de Administração Prisional $^{1}, 67$ jovens que compunham a amostra inicial encontravam-se ligados ao sistema prisional. Também identificamos 16 óbitos tomando como referência a amostra inicial, conforme levantamento realizado pelo Instituto Médico Legal de Belo Horizonte².

\footnotetext{
${ }^{1}$ Os dados foram levantados com a colaboração direta da 23a Promotoria de Justiça de Defesa dos Direitos das Crianças e dos Adolescentes - Área Infracional e do Centro de Apoio Operacional das Promotorias Criminais, Execução Penal, Tribunal do Júri e Auditoria Militar (CAOCRIM), representados pelos Promotores de Justiça Dr. Márcio Rogério de Oliveira e Dr. Henrique Nogueira Macedo, respectivamente, a quem agradecemos pela disponibilidade e parceria.

${ }^{2}$ Também aqui agradecemos aos Promotores de Justiça acima mencionados, bem como ao Diretor do Instituto Médico Legal de Belo Horizonte, Dr. Thales Bittencourt de Barcellos, pela disponibilização dos dados oficiais.
} 
Partindo dessa lista com 109 nomes que estiveram inseridos em espaços de atendimento socioeducativo, buscamos a oportunidade de analisar aspectos biográficos que influenciam a trajetória infracional e institucional. Desses, registramos as narrativas e aplicamos o questionário com 6 jovens. A razão entre o número inicial de nomes e o número final de entrevistas é um indicativo das dificuldades que encontramos em campo. Além das experiências com a institucionalização/aprisionamento e a vitimização por homicídios, constatamos que muitos jovens haviam se mudado e que outros se negaram a participar da pesquisa, como já pontuamos.

O trabalho transdisciplinar proposto possibilitou um levantamento de informações muito extenso, pois a amostra para aplicação do questionário e registro de Narrativa Memorialística foi bastante significativa, considerando o universo novo que se delineia com essa proposta investigativa. Além disso, como disposto anteriormente, optamos pelo estudo de caso em função da possibilidade de demonstrar uma perspectiva mais ampla do cenário, ao mesmo tempo em que não perdemos o enlace com riqueza de sua singularidade. Como resultado, objetivamos a construção de um olhar transdisciplinar, que congregue em si as potencialidades das disciplinas envolvidas, especialmente a psicanálise e a sociologia.

Assim, apresentaremos o caso de José, um jovem autodeclarado pardo, nascido em um território periférico do município de Belo Horizonte, cuja origem partiu de diversas ocupações na década de 1950, em uma área sem urbanização, que recebia populações pobres vindas de zonas rurais (Prefeitura de Belo Horizonte, 2018). Em 2014, época em que seu PIA foi construído, José tinha 16 anos e cumpria medida de semiliberdade, após um histórico de diversas passagens pelo sistema socioeducativo - a maioria delas por tráfico de drogas - e o recebimento de uma medida protetiva para o tratamento de toxicomania. Embora tenha escolaridade compatível com a $6^{\text {a }}$ série, os técnicos relataram que o jovem estava em processo de alfabetização. O PIA também cita que o jovem residia com sua mãe - que na ocasião tinha 35 anos de idade, trabalhava como diarista e não sabia ler - e com uma irmã de 23 anos de idade, que trabalhava como auxiliar de serviços gerais e possuía apenas a $2^{\text {a }}$ série do ensino fundamental. Em 2018, ocasião de nosso encontro com José, ele era um jovem de 20 anos, que afirmava não estar mais envolvido com atos infracionais após ter cumprido todas as pendências junto ao Sistema Judicial. Em seu questionário, informou estar matriculado no Programa de Educação de Jovens e Adultos (EJA), mas sem estar frequente. Morava com a mãe, a irmã e uma namorada, à época, grávida.

\section{Análise dos dados}

\section{“Querendo ou não, vivemos a violência do Estado"}

Devemos assinalar que os desafios do trabalho baseado em uma busca ativa foram vários $\mathrm{e}$ compuseram a riqueza e inovação metodológica dessa estratégia transdisciplinar. Dentre tais desafios, pontuamos com especial ênfase o que se revelou nas incursões territoriais como um acentuado processo de migração, em certa medida desbussolada, desses jovens. Identificamos um elevado deslocamento territorial dos jovens na medida em que a equipe não encontrava a população buscada com base em informações disponibilizadas 3 anos antes - a pesquisa documental tinha por referência o ano de 2015 e a investigação em território deu-se, majoritariamente, ao longo do ano de 2018.

Uma análise das informações levantadas demonstrou como tal processo migratório dos jovens estava calcado em fatores como: intervenções urbanísticas de órgãos municipais, que mudavam radicalmente a dinâmica territorial; urgência na desvinculação em relação ao movimento infracional, fortemente marcado pela territorialidade; dispersão em função da perseguição e ameaças por parte tanto dos agentes do Estado, quanto de grupos rivais no contexto da criminalidade; conflitos familiares; prisão; e expulsão por linchamento comunitário. Toda essa dinâmica territorial foi levantada com a mobilidade contínua dos pesquisadores em campo.

Nossa incursão no território na cidade de Belo Horizonte nos levou a conhecer áreas de alta concentração de desvantagens, com histórico de ocupação precária e desordenada, marcado por uma relação ambígua de abandono e resistência contra o poder público (Beato \& Zilli, 2012). Esse cenário revela uma segregação socioespacial semelhante à encontrada por Mello (1991, p. 6) em São Paulo: 
Parcelas significativas das camadas de renda mais baixa foram compelidas sistematicamente a se fixar nas periferias distantes, desprovida de infraestrutura urbana e de equipamentos sociais, com condições de habitabilidade e de vida incompatível com os padrões exigidos para o ser humano.

Nesses contextos, a venda de produtos roubados e falsificados, a realização de ligações clandestinas de internet e luz, a exploração de caça-níqueis e o tráfico de substâncias ilícitas se apresentam como alternativas naturais e legítimas para sobreviver às adversidades (Hirata, 2010). Nesses locais, os modos de produção da ordem e da lei são constantemente negociados e estão sempre em mudança, uma vez que os agentes lançam mão de vias legais e ilegais de modo simultâneo e negociam as regras e limites de modo que as próprias fronteiras entre o Estado de Direito e o Estado de Exceção se estendem ou são refeitas na busca por segurança. Assim, as margens se tornam o espaço ideal para compreender o funcionamento do Estado, pois lá se manifestam as questões de sua incompletude (Das \& Pole, 2004).

Nesse registro é possível compreender conexões internas entre lei e exceção, entre o Estado de Direito e o Estado de Exceção. Neste último, a multiplicação dos poderes de soberania produz uma relação em que uns têm o poder de matar e deixar viver, o que transforma alguns sujeitos naquilo que Agamben (2015) chama de homo sacer, a vida matável. Isso se verifica, por exemplo, nas relações entre policiais e traficantes baseadas na extorsão, na ameaça e na chantagem, pagas em dinheiro, armas e outros itens; na ação policial nas margens, que acusa e incrimina indivíduos mesmo antes do cometimento de atos ilícitos (Telles, 2010); bem como no assassinato e extermínio sumário de jovens pretos e pardos oriundos das periferias urbanas.

A realidade de Belo Horizonte não é diferente. A edição do Mapa da Violência dedicada ao tema "Homicídios por armas de fogo" aponta que em 2014 o município registrou 731 mortes por essa causalidade para a população total, $5^{\circ}$ maior número dentre as capitais brasileiras (Waiselfisz, 2016). Se por um lado a maior concentração de óbitos na população jovem é causada por homicídios, em contraposição, sabe-se que tal crime representa uma parcela mínima das infrações cometidas por jovens em Belo Horizonte. Na ocasião da 27ª Reunião Plenária do Fórum Permanente do Sistema de Atendimento Socioeducativo de Belo Horizonte, realizada em 2 de agosto de 2017, o Relatório Estatístico Anual do CIA/BH apresentado demonstrou que o índice de infrações caracterizadas como homicídio relativas aos adolescentes apreendidos em 2015 foi de $0,24 \%$. Tais cifras revelam que a corrente concepção de que a violência parte predominantemente do jovem tende a ser falaciosa, uma vez que os jovens mais morrem do que matam.

Quanto ao movimento de migração identificado, associado aos dados de homicídio elencados, José indica o fio condutor de sua trajetória infracional:

Morava com a minha mãe, com as minhas irmãse meu irmão... porque foi falecido lá [outro bairro]. Aí nós morava lá e depois nós foi... nós mudou pra cá, pra já; pra mim não... por causa d'eu não envolver lá, né?

O afastamento territorial não foi suficiente para que a trama sócio-simbólica e pulsional que o atravessava não o levasse a efeitos de repetição. No novo bairro, envolveu-se com atos infracionais a partir dos 7 anos de idade.

Essas condições desiguais produzem uma maior violência do Estado. José revela, a partir das questões do questionário destinadas a levantar informações a respeitodesuatrajetóriacomunitária, quefoiagredidorepetidas vezes pela polícia, dos 16 aos 18 anos, e aponta que o que menos lhe agrada em seu bairro é a violência policial. Mesquita Neto (1999) analisa como na América Latina a violência policial se consolidou a partir da herança de um dispositivo de violência estatal institucionalizado no período das ditaduras, em que a polícia atuava na manutenção dos regimes autoritários. O professor aponta que após a transição ao regime democrático no Brasil, "a violência policial enquanto tal não desapareceu, passando a ser usada sobretudo como instrumento de controle social e mais especificamente como instrumento de controle da criminalidade" (Mesquita Neto, 1999, p. 130). O autor ainda aponta para a dificuldade em circunscrever esses atos no contexto de abordagens policiais, na medida em que pode haver um "uso desnecessário ou excessivo da força para resolver pequenos conflitos ou para prender um criminoso, que, ... desde que seja relacionado ao cumprimento do dever legal, não é incluído entre os casos de violência policial" (Mesquita Neto, 1999, p. 133). 
Em meio a contextos tão estigmatizantes, temos uma passagem adolescente marcada por desigualdade, violência e morte; mas, como revela José: “Todos somos adolescentes”.

\section{"Querendo ou não, somos todos adolescentes"}

Parece-nos decisivo iniciar esta seção anunciando a dificuldade de produzir uma definição universal de adolescência e juventude. Muitas são as variáveis que marcam esse período da vida, que mobiliza diversos atores sociais, como família, pesquisadores, equipamentos de saúde e educação. Sabemos que a juventude é heterogênea, diversificada. "Nessa esfera, não existe um arquétipo, mas sobretudo, jovens marcados por seu sexo, classe social, local onde vivem, sua origem e a de seus pais, sua história pessoal, a situação relacional em que se situam" (Le Breton, 2009, p. 32). Não obstante tais atravessamentos sóciosimbólicos, podemos pensar um traço universal que atravessa a adolescência. Trataremos de tentar construir uma leitura possível que considere o tema e os atravessamentos da interface com a infração, tendo como bússola a narrativa de José.

$\mathrm{O}$ antropólogo francês Le Breton sugere que condutas de risco podem configurar-se como elemento comum na passagem adolescente. De acordo com ele, as condutas de risco recorrentes nesse período se apresentam como uma restauração narcísica, na medida em que estão ligadas à constituição de uma imagem. Na concepção do autor, o perigo e o desafio constituintes da conduta de risco possibilitam construir "uma imagem melhor de si mesmo; são um meio de construir uma identidade para si" (Le Breton, 2009, p. 41). Ou seja, “. . . são desvios simbólicos para assegurar-se do valor da própria existência, expulsar para o mais longe possível o medo de sua insignificância pessoal" (Le Breton, 2009, p. 41). Se tomarmos a experiência de José com o campo infracional, localizamos em sua narrativa uma conexão com o tema da conduta de risco: “. . porque no decorrer daquilo ali foi tudo uma fase. Não foi tudo... a ocorrência assim normal, porque muitas vezes é... é por emoção, pra mostrar pros outros. Pra mostrar que é aquilo".

Le Breton (2009) também indica que "ao manipular a hipótese de sua morte voluntária, o jovem aguça o sentimento de liberdade . . . . Desse modo, a morte entra na esfera de seu poder próprio" (p. 43). Dizendo sobre sua experiência com o envolvimento com a criminalidade, José nos indica: "Porque muitos acha, né? 'Ah, é fama, é poder, é aquilo...' Mas tudo tem consequência". Ainda segundo Le Breton (2009), a conduta de risco atesta o enfrentamento com o mundo, cuja aposta não é morrer, mas viver mais. 9acrescenta que o projeto é de nascer de si mesmo dentro do sofrimento e, assim, alcançar finalmente um significado de si que permita retomar o controle da própria vida.

José nos aponta um movimento reflexivo em meio à conduta de risco associada ao envolvimento com a criminalidade, que insistia num movimento subjacente à emoção, mostração ou curiosidade: "Você faz por gostar, mas querendo ou não sentia lá no fundo 'pra quê que você tá fazendo isso?'; 'De quê que vai adiantar?'; 'O quê que vai acontecer?". Dessa maneira vemos como a inserção da criminalidade, para além das altas taxas de mortalidade entre os jovens, não representa simplesmente lançar os corpos à morte, mas interrogar simbolicamente a morte para saber se vale a pena viver.

Le Breton (2009) nos oferece uma brilhante análise sobre as condutas de risco entre jovens e acreditamos que algumas das ideias anunciadas pelo autor se revelam como excelentes possibilidades de compreensão da movimentação de vida que produz como consequência as mortes de jovens pobres, negros e da periferia brasileira. Ao colocar a si mesmo ou a própria vida em risco, é experimentado "o sentimento de sua necessidade pessoal, do valor e do sentido de sua vida" (Le Breton, 2009, p. 39). O autor ressalta que a casuística para uma ação dessa ordem é complexa e pode se relacionar com diversos fatores:

Os motivos para por em perigo a própria vida a fim de existir são inúmeros e misturados, apenas a história pessoal do jovem é suscetível de esclarecer o sentido de sua passagem ao ato, uma vez que outro, vivendo situação semelhante, parece estar satisfeito com ela ou assume condutas diferentes. As condutas de risco têm sua origem no abandono, na indiferença familiar, mas também, ao contrário, na superproteção, especialmente materna (Le Breton, 2009, p. 39).

Por outro lado, interessa-nos apresentar uma problematização desse perigoso jogo entre vida e morte protagonizado pelos jovens, acrescentando à equação predicados como negritude, pobreza, gênero e territorialidades. O estabelecimento dessa 
tensão com seus atravessamentos subjetivos e sociais nos convocam a refletir uma aposta que, "querendo ou não", coloca em jogo o valor da própria existência. Frente às elevadas taxas de mortalidade entre jovens negros e pobres, moradores de periferia, conforme aprensentamos ao longo do trabalho, aventamos uma reflexão acerca da função da política genocida do Estado em relação a essa parcela da população e do peso de uma convocação ao pior que se coloca no enfrentamento com o mundo, no caso desses jovens, pela via das condutas de risco. Em outras palavras, refletimos como o contexto sociocultural brasileiro coloca o jogo com a morte das condutas de risco comuns na adolescência em um lugar de convocação ao desaparecimento, dado que esse contexto decorre da dívida histórica nunca reparada em relação à escravização no período colonial, cujos efeitos, que engendram um silenciamento declarado quanto às consequências derradeiras do passado de aniquilação da população negra e pobre, podem ser claramente encontradas numa política de extermínio institucionalizada. José nos diz que também um "embalo" pode marcar a entrada na criminalidade:

Porque, querendo ou não muitas pessoas entra por essa vida de embalo. Porque são muitas coisas chocantes que você vê lá dentro [do sistema socioeducativo]. Você vê nego querendo suicidar. "Pra quê que eu fui fazer isso? Pra quê que eu quero essa vida?". Porque às vezes não tem um apoio, uma sensibilidade de que que é, que é muito simples. "Ah, não sei porque eu entrei. Ah, não sei...".

Perguntamo-nos, portanto, o que embala os destinos dos jovens negros brasileiros de baixa renda, moradores de periferias? Como dissemos, o presente trabalho parte de um grupo de pesquisas que articula psicanálise e sociologia em um novo diálogo transdisciplinar. Para a psicanálise, o sujeito do inconsciente encontra-se entre a pulsão e suas representações que advêm do campo do Outro, sempre insuficientes para dar conta do excesso ou do movimento constante a que corresponde a pulsão. Assim, tem-se que "o inconsciente não pode ser apreendido em termos de idade cronológica" (Oliveira \& Hanke, 2017, p. 297). Portanto, pensar a adolescência a partir do campo da psicanálise configura-se um desafio, na medida em que se trata de um conceito eminentemente sociológico, demarcado cronologicamente, sob supostos pilares biológicos. A Sociologia busca entender como questões estruturais referentes a instituições como escola, trabalho e família modelam o que contemporaneamente chamamos de adolescência e preocupa-se em compreender os efeitos das interações sociais e das redes em que os sujeitos se inserem na formação de suas atitudes, valores, expectativas e no processo de transição para a vida adulta (Hughes, 1958; Goffman, 2007). Nesse sentido, mesmo que não seja nunca completamente apreendido pelas conformações socioculturais, o sujeito apresenta-se pelos efeitos de tal configuração por ser atravessado pela linguagem e localizado apenas no deslizamento do significante (Oliveira \& Hanke, 2017).

No que se refere aos efeitos da cultura, o grupo de sujeitos da pesquisa está historicamente contextualizado em um cenário de violências, vulnerabilidades e violações. É nesse contexto que tratamos de analisar o caso de José, tendo como tarefa pensar o singular do caso nos trajetos pulsionais apreendidos pelo discurso do jovem, bem como o universal que porta em relação aos atravessamentos culturais e modalidades de respostas sintomáticas.

Ozella e Aguiar (2008), que partem de uma abordagem sócio-histórica em seu estudo sobre a concepção da adolescência a partir do discurso de jovens estudantes cursando o ensino médio, advertem que por vezes a adolescência é apreendida de forma "naturalizante e aistórica" (p. 98). Em contraposição a tal postura, Ozella e Aguiar (2008) afirmam que para além da visão de um período de desenvolvimento biológico, a adolescência pode ser pensada "como um momento significado, interpretado e construído pelos homens” (p. 104). Eles ainda advertem que "quando definimos a adolescência como isto ou aquilo, estamos atribuindo significações (interpretando a realidade), com base em realidades sociais e em 'marcas', significações essas que serão referências para a constituição dos sujeitos" (Ozella \& Aguiar, 2008, p. 99).

$\mathrm{Na}$ interface entre a inscrição social, a apreensão discursiva, a impossibilidade de apreensão totalizante do movimento pulsional, que envolve toda constituição subjetiva, perguntamo-nos: como pensar a adolescência no contexto já mencionado de uma parcela da população dos jovens brasileiros?

Oliveira e Hanke (2017) nos lembram que Freud utiliza o termo puberdade ao tratar dos tempos de constituição da sexualidade humana e, portanto, da subjetividade. Para o vienense, trata-se da 
irrupção de um tempo em que há um redespertar da sexualidade, que estrutura as relações humanas: antes infantil e latente, ela desperta quando as injunções da cultura passam a incidir mais fortemente sobre o sujeito. Tal redespertar é corolário de um tempo de destituição das imagos parentais, de um movimento de separação e de desarranjo da disposição infantil das pulsões parciais.

Lacan, psicanalista francês que se empenhou numa tarefa exímia de leitura do texto freudiano que denominou de "retorno a Freud", analisará esse tempo como um encontro com o real. Sem confundir-se com a realidade empírica, factual, o real lacaniano designa o registro do que, em termos psíquicos, "não para de não se escrever”; ou seja, é "o impossível ... [porque] ele não pode, em nenhum caso, escrever-se" (Lacan, 1972-1973/2008, p. 101). O real lacaniano está, portanto, fora do campo da significação ou do sentido para o sujeito. De uma perspectiva freudo-lacaniana, entendemos que "a adolescência se apresenta como uma série de respostas sintomáticas ao encontro com o real promovido pela puberdade" (Oliveira \& Hanke, 2017, p. 300).

A Sociologia, de um ponto de vista interacionista, entende a adolescência como uma fase de transição para a vida adulta - estruturada no advento da modernidade e cada vez mais alongada com seu avanço na qual os indivíduos perdem uma série de privilégios atribuídos à infância e progressivamente adquirem deveres, privilégios e expectativas tipicamente associados ao mundo adulto (Hughes, 1958).

Perguntamos, então, o que José nos orienta sobre esse tempo? O jovem é categórico: "querendo ou não, nós somos todos jovens comuns, no meio da sociedade". A irrupção de um tempo à revelia do querer ou da escolha aponta para um universal que, para esse jovem, parece dever ser lembrado, marcado, afirmado e mesmo reivindicado. O que será que permeia tal reivindicação?

Poderíamos pensar como, no encontro com o impossível de significar, na irrupção de um encontro faltoso, onde falha a fantasia infantil, todos os jovens tentam construir sua resposta em meio à sociedade. José nos relembra disso ao enfatizar o caráter disruptivo, fora do campo da escolha, que atravessa a adolescência. E no caso de José, jovem com histórico de ato infracional e passagem por sistema socioeducativo, é essencial que ele nos lembre de uma resposta sempre em construção.
José constrói, antes de mais nada, uma mensagem sobre seu tempo, sua verdade, sua história. Ele nos mostra que no momento em que a "disjunção entre a pulsão e o Outro" (Oliveira \& Hanke, 2017, p. 303) irrompe, é preciso ainda lembrar que "o lugar do Outro permanece sendo sempre o lugar para onde o sujeito dirige suas questões" (Oliveira \& Hanke, 2017, p. 304). Os autores aqui citados pontuam tal lugar para lembrar a importância de pensarmos as especificidades temporais e espaciais da cultura e os atravessamentos delas nos sujeitos; mas podemos também pensar, analisando o que nos apresenta José, a importância do que poderá enlaçar o sujeito, apresentando-se como possibilidade de referência. Ele nos diz repetidamente: "Porque querendo ou não nós somos todos jovens comuns, no meio da sociedade. Só alguns que precisam de ajuda, uns que não querem sair" - sair da alienação de circuitos mortíferos, da apreensão discursiva recriminante, condenatória e determinante, do não-lugar. José é categórico: "Você ter o apoio, isso completamente muda". Essa parece ser uma direção imperativa no trabalho com as juventudes envolvidas em situações de violações e violências, pois, como nos indica Le Breton (2009, p. 40):

O que ele não encontra mais em si mesmo a certeza interior de que sua vida é valiosa e que ele tem seu lugar no mundo - o jovem procura em outra parte, de maneira desordenada e em corpo a corpo com o real.

\section{“Querendo ou não, a morte está próxima"}

Retomando a afirmação de José, "Porque querendo ou não nós somos todos jovens comuns, no meio da sociedade. Só alguns que precisam de ajuda...", podemos interpretar essa demanda de diferentes maneiras. Todavia, consideramos que o tema da mortalidade/letalidade juvenil exige sempre uma intervenção social. Sabemos que o índice de suicídios entre a população jovem (15 a 19 anos) aumentou gradativamente no Brasil e que figura atualmente como a terceira causa de morte entre essa população, ficando atrás de violência interpessoal e do acidente de trânsito, de acordo com os dados da Organização Mundial de Saúde, publicados em 2017 (Wentzel, 2017).

O contato cotidiano com o assassinato de jovens amigos e parentes marca essa população de jovens majoritariamente negros e de periferia. Corroborando 
com os dados estatísticos, José, no processo de narrativa de sua vida, nos revela:

Pra trazer esses atos infracionais que eu cometi, tudo tem um motivo. Começou quando eu morava em [bairro do município de Belo Horizonte], foi 2005, dia 25 de março. Tudo começou com o falecimento da morte do meu irmão ... Querendo ou não eu vi a morte do meu irmão, querendo ou não abala. Aí você...

Entrevistadora: Você tinha quantos anos?

Eu tinha 7. Aí você vê, querendo ou não fica na máquina, você quer vingar de qualquer forma, de qualquer jeito. Mas é... é tipo que não saía da minha mente isso. Aí eu comecei.

Enquanto em sua narrativa José localiza o ponto de entrada na criminalidade no assassinato do irmão, seu PIA indica como principal fator o uso de drogas, apresentando o tratamento para toxicodependência como capaz de quebrar o circuito que impulsiona sua trajetória infracional. O documento institucional foi escrito da seguinte forma:

José fala de sua trajetória infracional em que se destaca seu envolvimento com tráfico, o adolescente conta que iniciou tal prática para consumir sua própria droga, dando assim, um importante indicativo de como inicia a trajetória. ... Deste modo o uso de drogas parece compor um circuito que se retroalimenta e impulsiona a trajetória infracional.

No entanto, a narrativa revela que é a impossibilidade de elaboração do luto pela morte do irmão que lança José no círculo de vingança, que se transmite "de geração em geração, criando inimigos perpétuos; é como uma cadeia ou círculo de violência da qual se faz difícil sair" (Ramírez, 2016). Isso revelao papel das expectativas do outro sobre a ação do sujeito e como ela desperta questionamentos sobre os valores a serem seguidos e as atitudes a serem tomadas. A interpelação dos outros no sentido da vingança pela morte do irmão é uma exigência normativa que se relaciona com valores transcendentais (Bertaux, 2014), como a lealdade familiar e a reciprocidade, ainda que seja agonística com o autor do homicídio de seu irmão. Mas José percebe que há algo de concretamente irreparável nesse circuito:
Porque querendo ou não, porque aí tipo... muitos embalo vem, tipo muita gente ainda fala "totalmente apoio"; tipo assim... ninguém sabe, mas muitos chegava perto de mim: "você não vai vingar não?"; "você não vai fazer isso não?". Querendo ou não, isso abala seu psicológico, você fica: "não... nada não, [inaudível], sei quê lá..." "Você deixou?". Porque querendo ou não, você vai escutando isso, depois você vai percebendo: "se eu matar esse cara, quem é que vai trazer ele de volta? Será que vai resolver alguma coisa?".

Segundo Butler (2015), a sociedade determina condições normativas, historicamente contingentes, para definir vidae não-vida. Nas palavras da autora, "há 'sujeitos' que não são exatamente reconhecíveis como sujeitos e há 'vidas' que dificilmente - ou, melhor dizendo, nunca - são reconhecidas como vidas" (Butler, 2015, p. 17). A autora trata dos enquadres sociais que definem quais são as vidas passíveis de luto a partir de uma reflexão sobre os quadros de guerra contemporâneos, especificamente as guerras estadunidenses com o Oriente Médio. Aqui consideramos que essa reflexão pode oferecer subsídios para pensarmos as situações dos jovens que estejam envolvidos com a criminalidade, que por vezes nomeiam os conflitos e disputas territoriais para venda de drogas como guerras.

Para Butler (2015), "certas vidas não são qualificadas como vidas, ... não são concebíveis como vidas de acordo com certos enquadramentos epistemológicos" (p. 13). A filósofa ainda pontua que "a possibilidade de ser enlutado é um pressuposto para toda vida que importa" (Butler, 2015, p. 32). E acrescenta: "sem a condição de ser enlutada, não há vida, ou, melhor dizendo, há algo que está vivo, mas que é diferente de uma vida" (Butler, 2015, p. 33).

As molduras sociais e políticas delimitam nosso campo de visão estabelecendo distinções valorativas entre as vidas humanas. Toda vida é marcada por uma precariedade, pelo desamparo, mas algumas vidas podem contar com o pacto social, que resulta no ingresso no "circuito de intercâmbio social" (Pellegrino, 1983) para oferecer o amparo possível; outras recebem um amparo deficiente ou, pior, não recebem amparo algum. Nas palavras de Butler (2015), "a condição precária designa a condição politicamente induzida na qual certas populações sofrem com redes sociais e econômicas de apoio deficientes e ficam expostas de forma diferenciada às violações, 
à violência e à morte" (p. 46). Lembremos, por exemplo, a quantidade de adolescentes de nossa lista inicial que não entraram no recorte de busca ativa em função de dados carcerários e obituários.

Em relação à Lei da Cultura a que somos submetidos no circuito social, no caso de jovens que cometem algum ato infracional - ou que são de antemão apreendidos em um tecido discursivo estigmatizante - parece haver uma ruptura do pacto social (Pellegrino, 1983), resultando na ascensão dessas vidas ao desamparo. O seguinte trecho do relato de José demonstra essa ruptura e seu consequente desamparo:

Porque às vezes você ter passagem, você ir com o socioeducativo, porque você vai ver o quê que a sociedade, porque você aqui fora, você como bandido aqui, muitos te conhece como bandido. Mas lá fora quando você aparece preso, no socioeducativo, você já viu os olhares das pessoas, como que é?

Toda vida humana precisa contar com recursos fora de si para garantir a existência, mas as vidas denominadas como vulneráveis dependem, para sua mera sobrevivência, "de condições e instituições sociais, o que significa que, para 'ser' no sentido de 'sobreviver', o corpo tem de contar com o que está fora dele" (Butler, 2015, p. 58), mas esses recursos não estão necessariamente à disposição. Nesse contexto, estas vidas podem se configurar apenas como dado estatístico: transformam-se em números de uma política, inclusive número de óbitos, indicando um devastador quadro de letalidade juvenil. Butler (2015) anuncia que estas vidas não passíveis de luto, desamparadas, em precariedade, não importam como vidas:

Essas populações são "perdíveis", ou podem ser sacrificadas, precisamente porque foram enquadradas como já tendo sido perdidas ou sacrificadas; são consideradas como ameaças à vida humana como a conhecemos, e não como populações vivas que necessitam de proteção contra a violência ilegítima do Estado, a fome e as pandemias. (Butler, 2015, p. 53)

O tema do amparo viável aparece como uma possibilidade de intervenção com esses jovens estatisticamente condenados à morte. No campo das políticas públicas, a oferta de amparo como alternativa às cifras letais da juventude brasileira parece-nos um importante indicador da construção de caminhos que levem em conta a vida e inscrevam esses jovens no intercâmbio social. A título de exemplo, citamos Gallo e Williams (2008), que concluem, a partir da análise de 123 prontuários, referentes ao ano de 2002 , de jovens inseridos no sistema socioeducativo no interior de São Paulo, que a frequência na escola impactou na redução da gravidade do ato infracional, do uso de armas e de drogas. Vemos, portanto, a possibilidade de um amparo possível, nesse caso, institucional. Mas podemos ainda pensar diversas e plurais formas de alças que possam sustentar os jovens em sua passagem adolescente.

\section{“Querendo ou não, é preciso apostar"}

Quanto à constituição humana, entendemos que o desamparo é originário. Fica circunscrito a partir do momento em que o bebê depende fundamentalmente do amparo de um outro para sobreviver. O ser é assim entregue a uma passividade primordial. Durante a puberdade, irrompem moções pulsionais no interior do sujeito, que têm por efeito atualizar a situação de desamparo, uma vez que as defesas psíquicas infantis não são mais cabíveis e o movimento é de separar-se da alienação fundante em relação ao outro em que está imersa a criança. Porém, na adolescência, o ser não é apenas passividade, mas se encontra equipado com alguns recursos psíquicos, inclusive resistências (Guerra \& Moreira, 2020). Na medida em que o desamparo é uma ferida incurável na constituição psíquica, entendemos que as resistências que surgem em relação ao socorro do outro, são fundamentais no reconhecimento da alteridade e na construção de possíveis saídas de uma situação irremediável. Afinal, como aponta José:

Porque tem gente que vai querer ver seu bem, outros vão querer te ver seu mal, querer ver você da mesma forma que ele está. Porque querendo ou não, muitos que estão nessa vida vão te dar conselho "faz isso aí que você quer", "essa vida que você quer"... que é de sofrimento.

A travessia da adolescência e seu consequente encontro com o real, a partir da vacilação do amparo e da imagem dos pais enquanto invencíveis, impõe ao adolescente a necessidade de construção de si mesmo sobre outras bases. Assim, como apontado anteriormente, a adolescência reafirma o desamparo e o ato de se lançar à vida é o movimento próprio do 
jogo da aposta. A aposta "se refere ao real absoluto trata-se do que não se pode saber se é, nem o que é" (Pitteri, 2012, p. 3), ou seja, aquilo que não tem resposta nem representação possível. Em outras palavras, estar vivo lança o sujeito a um apostar no intangível, a dar certa consistência subjetiva ao Outro que está para além de si mesmo, para que ele próprio possa se constituir enquanto singularidade independente das heranças ou imposições familiares.

A necessidade do amparo que constitui a condição humana não é sem reação do ser, essencial para que todo socorro se constitua enquanto uma aposta. José nos aponta como a aposta comporta um espaço de emergência de resistências que demarcam uma distância do outro - trabalho característico da adolescência -, mas simultaneamente uma oferta de enlaçamento que permita uma decisão dos jovens:

Porque lá [no cumprimento de medida socioeducativa], eles vão te dar totalmente trajetória, eles vai querer perguntar: "É isso que você quer? Você vai querer continuar dessa forma? Nós estamos aqui para te ajudar, a sua decisão você escolhe. Você quer mudar, você pode mudar". . . . Porque, pesquisa né, essa é a segunda vez que eu faço. Que eu fiz com... com um professor de teatro da França. . . . Isso ajudou mais a você conhecer. Que ele veio pra poder fazer a pesquisa, como é que é... estudar e trabalhar junto com os jovens. Fazer um teatro. Aquilo ali acabava não querendo, abriu a nossa mente. "Será que é isso mesmo que nós quer?". Porque... porque querendo ou não, tem muitas trajetórias de vidas, as vidas é cheias de altos momentos e baixos, mas decide se você quer mudar. Ou se você não quer. A escolha é totalmente sua, porque antigamente era, como se diz, aquele menino que não ligava pra nada, tava nem aí.

Da passividade de um jovem que não ligava para nada, a partir de uma oferta resoluta caracterizada por uma aposta, pode emergir um sujeito que se responsabiliza, que decide, ainda que sob um fundo de incerteza, ao invés de ficar à deriva dos atravessamentos de situações sociais precárias. A condição de sujeito se revela, portanto, como de um ser cuja estrutura indecidível força uma decisão que pode ser melhor enlaçada a depender da oferta. Para José, a medida socioeducativa se caracterizou como uma alternativa importante ao fazer vacilar um circuito mortífero. No entanto, frisamos a importância significativa da aposta que ele vislumbrou. O que nos pareceu decisivo não foi, portanto, a medida, tendo em vista que ela pressupõe situações de violências e violações, mas eminentemente o encontro com uma aposta decidida:

Que, querendo ou não quando eu fui preso, quando eu fui preso pela segunda vez que eu fui transferido pro ceipão [como os jovens nomeiam o Centro de Internação Provisória], que depois que fui pra casa de semi [medida socioeducativa de semiliberdade], isso ajudou realmente. Ajudou muitos jovens mudar de vida, porque lá eles vai ver o que é a perseverança de vida. Eles vai entender se é isso que eles quer pra vida deles ou se é isso que eles não quer. Porque lá o cara muda se ele quiser. Se ele querer mudar, ele vai mudar. Se não querer vai continuar da mesma forma. Porque vai ter psicóloga e acompanhando, vai ter outras pessoas te acompanhando. Advogado. Vai ter curso. Você vai... Você vai aprendendo a viver no meio da sociedade.

Uma aposta decidida, portanto, devolve a confiança em um pacto social de mão dupla, no âmbito das relações interpessoais (Pellegrino, 1983). José pode ainda ter outro encontro fortuito, com sua companheira: “. . . porque ela [namorada] mostrou confiança, ela confiou em mim. Porque, outras pessoas não confiou. Muitas pessoas viraram: 'logo, logo tá de volta'... Querendo ou não um apoio, já te ajuda, a confiança".

Dessa vez, portanto, o que surge à revelia de sua vontade é uma aposta que, "querendo ou não", convoca uma nova decisão, novas saídas:

Porque querendo ou não, muitos que estão nessa vida vão te dar conselho. Vão te falar: "é isso que você quer? É essa vida mesmo que você quer? Que é de sofrimento". Mas só que eu escolhi outra, minha vida tomou outro rumo, agora tô tranquilo, tô de boa, não cometo mais atos infracionais. .. . Tem que pensar e também o apoio dos familiares, de alguns né, de nunca desistir. E ir seguindo pela frente. 


\section{Considerações finais}

Ao analisarmos o curso de vida de José, investigando a respeito de transições e rupturas, de eventos que fazem marcas significativas em suas trajetórias, encontramos que, em sua singularidade, esse sujeito nos revela aspectos universais da experiência do adolescente autor de ato infracional, reunidos nos quatro elementos identificados na investigação: violência do Estado, experiência adolescente, mortalidade juvenil e aposta inconsciente. Trata-se de elementos estruturais a serem enfrentados no combate à juvenilização da população carcerária e à racialização do genocídio da população jovem brasileira, implicando a transdisciplinaridade não apenas na análise, mas na necessária composição de respostas à superação dos impasses que concernem a essa população.
Sugerimos a necessidade de expandir a reflexão sobre a aposta para outros campos institucionais e estruturas sociais, considerando, por exemplo, que o jovem desistente ainda não havia rompido com o ciclo de evasão escolar que caracterizava sua trajetória e que as informações sobre o trabalho contidas no questionário apontam que não estava trabalhando no momento da narrativa. Qualquer aposta deve também ampliar a estrutura de oportunidades disponíveis a fim de possibilitar o rompimento com ciclos de vulnerabilidades e minimizar a transmissão intergeracional de desvantagens sociais. Entendemos que a perspectiva metodológica (Guerra, Marinho, Silva, \& Lelles, 2019) delineada na presente pesquisa indica vias de trabalho importantes às políticas públicas no levantamento das demandas que viabilizem vislumbramos caminhos de ofertas condizentes com uma aposta pela vida.

\section{Referências}

Agamben, G. (2015). Estado de exceção: Homo Sacer, II, I. Boitempo.

Beato, C., \& Zilli, L. F. (2012). A estruturação de atividades criminosas: um estudo de caso. Revista Brasileira de Ciências Sociais, 27(80), 71-88. https://doi.org/10.1590/S0102-69092012000300005

Bertaux, D. (2014). A vingança do curso de ação contra a ilusão cientificista. Cívitas: Revista de Ciências Sociais, 14(2), 250-271. https://doi.org/10.15448/1984-7289.2014.2.17147

Butler, J. (2015). Quadros de guerra: quando a vida é passível de luto? Civilização Brasileira.

Dantas, R. C. deO., Dantas, R. C.deO.,\&Cabral, S.A.A.deO.(2020).Violência policial:dor, cor elugar. RevistaInterdisciplinar em Violência e Saúde, 3(2), 1-12. https://editoraverde.org/portal/revistas/index.php/revis/article/view/154

Das, V., \& Pole, D. (2004). Anthropology in the margins of the State. School of American Research Press.

Fernandes, E. F. (2008). Narcisismo e cultura: a relação entre psicologia individual e psicologia social na obra freudiana [Dissertação de mestrado, Universidade Federal de São Carlos]. Repositório Institucional Ufscar.

Freud, S. (1996). Os instintos e suas vicissitudes. In S. Freud, Obras Psicológicas Completas de Sigmund Freud (Vol. 14, Edição Standard). Imago. (Originalmente publicado em 1915).

Gallo, A. E., \&Williams, L. C. de A. (2008). A escola como fator de proteção à conduta infracional de adolescentes. Cadernos de Pesquisa, 38(133), 41-59. https://doi.org/10.1590/S0100-15742008000100003

Goffman, E. (2007). Manicômios, prisões e conventos. Perspectiva.

Guerra, A. M. C., Broide, E. E., Moreira, I. G., \& Aranha, A. M. C. (2015). Do sujeito suposto suspeito às possibilidades de suposição de saber. In A. M. C. Guerra, P. D. M. Penna \& S. N. Soares (Orgs.), Direito e Psicanálise II: o adolescente em foco (pp. 30-49). CRV.

Guerra, A. M. C., Marinho, F. C., Silva, A. C. D., \& Lelles, A. L. X. (2019). Sobre a transdisciplinaridade em ato na pesquisa científica: aspectos metodológicos para discussão acerca da investigação sobre "curso de vida e trajetória delinquencial de jovens e adolescentes”. Psicologia em Revista, 25(1), 348-364. https://doi.org/10.5752/P.1678-9563.2019v25n1p348-364

Guerra, A. M. C., \& Moreira, J. de O. (2020). O Nebenmensch e o desamparo: alças possíveis para adolescências contemporâneas. In A. M. C. Guerra \& Moreira, J. de O. (Orgs.), Adolescências e narrativas memorialísticas: escutando apostas inconscientes (pp. 175-186). EDUNISC. 
Guerra, A. M. C., Moreira, J. de O., Oliveira, L. V. de, \& Lima, R. G. e. (2017). The Narrative Memoir as a Psychoanalytical Strategy for the Research of Social Phenomena. Psychology, 8(8), 1238-1253. https://doi.org/ $10.4236 /$ psych.2017.88080

Hirata, D. V. (2010). Sobreviver na adversidade: entre o mercado e a vida [Tese de Doutorado, Universidade de São Paulo]. Biblioteca Digital de Teses e Dissertações da USP. http://www.teses.usp.br/teses/disponiveis/8/8132/ tde-03032011-122251/pt-br.php

Hughes, E. C. (1958). Men and their work. The Free Press of Glencoe.

Lacan, J. (2008). O Seminário, livro 20: mais, ainda. (M. D. Magno, Trad., Texto estabelecido por J. Alain-Miller). Zahar. (Campo freudiano no Brasil). (Originalmente publicado em 1972-1973).

Le Breton, D. (2009). Condutas de risco: dos jogos de morte ao jogo de viver (L. L. de Oliveira, Trad.). Autores Associados.

Lei n. 8.069, de 13 de julho de 1990. Dispõe sobre o Estatuto da Criança e do Adolescente e dá outras providências. https://www2.senado.leg.br/bdsf/bitstream/handle/id/534718/eca_led.pdf

Lei n. 12.594, de 18 de janeiro de 2012. Institui o Sistema Nacional de Atendimento Socioeducativo (Sinase). https://central3.to.gov.br/arquivo/422114/

Lima, R. G., Wermelinger, C., Oliveira, L. C. P. de, \& Silva, B. F. A. da. (2019). Trajetórias e Narrativas de adolescentes envolvidos com a criminalidade: os objetos e suas formas de aproximação em transdisciplinaridade. Psicologia em Revista, 25(1), 365-380. https://doi.org/10.5752/P.1678-9563.2019v25n1p365-380

Mello, M. C. P. F. de. (1991). Segregação sócio-espacial na cidade de São Paulo e marginalização da criança e do jovem. Cadernos de Pesquisa, 78, 5-16.

Merton, R. K. (1966). Social Theory and Social Structure. The Free Press.

Mesquita Neto, P. (1999). Violência policial no Brasil: abordagens teóricas e práticas de controle. In: D. C. Pandolfi, J. M. de Carvalho, L. P. Carneiro \& M. Grynszpan (Orgs.), Cidadania, Justiça e Violência (pp. 130-148). Fundação Getulio Vargas.

Moreira, J. de O., Albuquerque, B. S. de, Rocha, B. F., Rocha, P. M. da, \&Vasconcelos, M. A. M. (2015). Plano Individual de Atendimento (PIA) na perspectiva dos técnicos da semiliberdade. Serviço Social \& Sociedade, (122), 341-356. https:// doi.org/10.1590/0101-6628.026

Moreira, J. de O., Rena, A. C. C. B., Bolaños, D. F, \& Oliveira, L. C. P. de. (2019). Teoria Crítica e Transdisciplinaridade: uma aposta no projeto emancipatório. Psicologia em Revista, 25(1), 330-347. https://doi.org/10.5752/P.1678-9563.2019v25n1p330-347

Moreira, J. de O., Rosário, A. B., \& Santos, A. P. dos. (2011). Juventude e adolescência: considerações preliminares. Psico, 42(4), 457-464.

Oliveira, H. M., \& Hanke, B. C. (2017). Adolescer na contemporaneidade: uma crise dentro da crise. Ágora: Estudos em Teoria Psicanalítica, 20(2), 295-310. https://doi.org/10.1590/1809-44142017002001

Ozella, S., \& Aguiar, W. M. J. de. (2008). Desmistificando a concepção de adolescência. Cadernos de Pesquisa, 38(133), 97-125. https://doi.org/10.1590/S0100-15742008000100005

Pellegrino, H. (1983). Pacto social e pacto edípico. Folha de S.Paulo, 11(9).

Pitteri, M. B. S. de S. (2012). Lacan e a aposta de Pascal. Opção Lacaniana online nova série, 3(7), 1-6. http://www.opcaolacaniana.com.br/nranterior/numero7/texto6.html

Prefeitura de Belo Horizonte. (2013). Diagnóstico da situação da criança, do Adolescente e do jovem em Belo Horizonte: Livro 10. Sistema de garantia de direitos da criança e do adolescente. Unilivrecoop. https://prefeitura.pbh.gov.br/sites/default/files/estrutura-de-governo/smasac/2018/documentos/cmdca/ livro_10_2013_diagnostico_cmdca.pdf

Prefeitura de Belo Horizonte. (27 mar. 2018). História de bairros. https://prefeitura.pbh.gov.br/ fundacao-municipal-de-cultura/arquivo-publico/informacoes/historia-de-bairros

Ramírez, M. E. (2 nov. 2016). Clase 9. Sujeto, Memoria y Conflicto. Blog Mario Elkin Ramírez - Psicoanalista. https://marioelkin.com/tag/agresividad/

Rolim, M. (2018). Desistência do crime. Sociedade e Estado, 33(03), 829-847. https://doi.org/ $10.1590 / \mathrm{s} 0102-6992-201833030008$ 
Salata, A. (2019). Razões da evasão: abandono escolar entre jovens no Brasil. Interseções, 21(1), 99-128. https://doi.org/10.12957/irei.2019.42305

Sampson, R., \& Laub, J. (2005, november). A Life-Course View of the Development of Crime. Annals of the American Academy of Political and Social Science, 602(1), 12-45. https://doi.org/10.1177/0002716205280075

Telles, V. da S. (2010). A cidade nas fronteiras do legal e ilegal. Argumentum.

Waiselfisz, J. J. (1998). Mapa da Violência: os jovens do Brasil. Juventude, violência e cidadania. Garamond Ltda.

Waiselfisz, J. J. (2016). Mapa da violência 2016: Homicídios porarmas de fogo no Brasil. (Versão Corrigida26/08/2015). Flacso Brasil. http://flacso.org.br/files/2016/08/Mapa2016_armas_web.pdf

Waiselfisz, J. J. (2017). Notas de Homicídio 4: Homicídios de Crianças e Adolescentes no Brasil. Instituto Igarapé. https://igarape.org.br/wp-content/uploads/2017/12/2017-12-04-Homicide-Dispatch_4_PT.pdf

Wentzel, M. (16 maio 2017). Violência, trânsito, doenças: O que mais mata os jovens no Brasil e no mundo, segundo a OMS. BBC News Brasil. https://www.bbc.com/portuguese/brasil-39934226

\section{Jacqueline de Oliveira Moreira}

Doutora em Psicologia Clínica pela Pontifícia Universidade Católica de São Paulo (PUC-SP), São Paulo - SP, Brasil. Mestre em Filosofia pela Universidade Federal de Minas Gerais (UFMG), Belo Horizonte - BH, Brasil. Professora do Programa de Pós-Graduação em Psicologia da Pontifícia Universidade Católica de Minas Gerais (PUC-Minas), Belo Horizonte - BH, Brasil. Bolsista Produtividade PQ2 do CNPQ.

E-mail: jackdrawin@yahoo.com.br

(1) https://orcid.org/0000-0003-0901-4217

\section{Andréa Máris Campos Guerra}

Doutora em Teoria Psicanalítica pela Universidade Federal do Rio de Janeiro (UFRJ), Rio de Janeiro - RJ, Brasil, com período sanduíche na Université de Rennes II, Rennes, França. Mestre em Psicologia pela Universidade Federal de Minas Gerais (UFMG), Belo Horizonte - BH, Brasil. Professora do Departamento e do Programa de Pós-Graduação em Psicologia da Universidade Federal de Minas Gerais (UFMG). Bolsista Produtividade PQ2 do CNPQ.

E-mail: andreamcguerra@gmail.com

(1) https://orcid.org/0000-0001-5327-0694

\section{Frederico Couto Marinho}

Doutor em Sociologia pela Universidade Federal de Minas Gerais (UFMG), Belo Horizonte - BH, Brasil, com período sanduíche na Universidade de Lille 1/Clersé. Mestre em Sociologia pela Universidade Federal de Minas Gerais (UFMG). Professor Adjunto do Departamento de Geografia; Coordenador do Curso Turismo do Instituto de Geociências; Professor do Programa Pós-Graduação Prevenção da Violência do Departamento de Medicina da Universidade Federal de Minas Gerais (UFMG). Pesquisador do Centro de Estudos de Criminalidade e Segurança Pública (CRISP).

E-mail: fcfrederico9@gmail.com

(1) https://orcid.org/0000-0002-1405-3125

\section{Bráulio Figueiredo Alves da Silva}

Doutor e Mestre em Sociologia pela Universidade Federal de Minas Gerais (UFMG), Belo Horizonte - BH, Brasil. Professor Adjunto do departamento de Sociologia da Universidade Federal de Minas Gerais (UFMG). Pesquisador do Centro de Estudos de Criminalidade e Segurança Pública e do Centro de Pesquisas Quantitativas em Ciências Sociais da Universidade Federal de Minas Gerais (UFMG). Bolsista Produtividade PQ 2 do CNPq. Apoiado pela FAPEMIG, processo APQ-02325-18, e CNPq, processo 306131/2018-8. 
E-mail: braulio.fas@gmail.com

(1) https://orcid.org/0000-0003-1791-9075

\section{Bianca Ferreira Rodrigues}

Mestre e graduada em Psicologia pela Universidade Federal de São João del-Rei (UFSJ), São João del-Rei - BH, Brasil. Doutoranda pelo Programa de Pós-Graduação em Psicologia da Pontifícia Universidade Católica de Minas Gerais (PUC-Minas), Belo Horizonte - BH, Brasil. Bolsista Capes.

E-mail: biancaferreira025@gmail.com

(1) https://orcid.org/0000-0002-7877-6808

\section{Ana Carolina Dias Silva}

Graduada em Psicologia pela Universidade Federal de Minas Gerais (UFMG), Belo Horizonte-BH, Brasil, com ênfase em Processos Clínicos/Formação Complementar Aberta em Subjetividades Políticas e Territórios. Doutoranda e Mestre em Psicologia pela Pontifícia Universidade Católica de Minas Gerais (PUC-Minas), Belo Horizonte - BH, Brasil. Bolsista Capes.

E-mail: acdsilva.psi@gmail.com

(1) https://orcid.org/0000-0002-5448-7622

\section{Lucas Caetano Pereira de Oliveira}

Graduado em Ciências Sociais e Mestre em Sociologia pela Universidade Federal de Minas Gerais (UFMG), Belo Horizonte - BH, Brasil. Integrante do grupo de Pesquisa Curso de Vida e Trajetória Delinquencial: um estudo exploratório dos eventos e narrativas de jovens em situação de vulnerabilidade.

E-mail: kaetanolucas@gmail.com

(1) https://orcid.org/0000-0001-6587-0937

Endereço para envio de correspondência:

Pontifícia Universidade Católica de Minas Gerais. Av. Itaú, 525, Jardim São José. CEP: 30535-012. Belo Horizonte MG. Brasil.

Recebido 08/12/2019

Aceito 03/02/2021

Received 12/08/2019

Approved 02/03/2021

Recibido 08/12/2019

Aceptado 03/02/2021

Como citar: Moreira, J. de O., Guerra, A. M. C., Marinho, F. C., Silva, B. F. A. da, Rodrigues, B. F., Silva, A. C. D.,\& Oliveira, L. C. P. de. (2022). Trajetórias adolescentes e infração: José, entre a morte e a aposta. Psicologia: Ciência e Profissão, 42, 1-17. https://doi.org/10.1590/1982-3703003231908

How to cite: Moreira, J. de O., Guerra, A. M. C., Marinho, F. C., Silva, B. F. A. da, Rodrigues, B. F., Silva, A. C. D., \& Oliveira, L. C. P. de. (2022 Adolescent trajectories and infraction: José between death and the wager. Psicologia: Ciência e Profissão, 42, 1-17. https://doi.org/10.1590/1982-3703003231908

Cómo citar: Moreira, J. de O., Guerra, A. M. C., Marinho, F. C., Silva, B. F. A. da, Rodrigues, B. F., Silva, A. C. D.,\& Oliveira, L. C. P. de. (2022). Trayectorias e infracciones de adolescentes: José, entre la muerte y la apuesta.

Psicologia: Ciência e Profissão, 42, 1-17 https://doi.org/10.1590/1982-3703003231908 